\title{
Childhood lead poisoning
}

Sri Lanka Journal of Child Health, 2000; 29: 125

In an article published in the September issue of the Sri Lanka Journal of Child Health it was stated that lead poisoning has not been documented much in Sri Lanka. I wish to bring to the notice of the authors 2 publications by Dr. E. H Mirando and co-authors. These publications, recorded in the Bibliography of medical publications relating to Sri Lanka 1811-1976 by Kamalika Pieris and C G Uragoda, are as follows.

- Mirando EH, Gomez M. Lead Poisoning in Childhood in Ceylon. Archives of Diseases in Childhood, 1967; 42: $579-82$.

- Mirando EH, Ranasinghe L. Lead encephalopathy in children; uncommon clinical aspects. Medical Joumal of Australia, 1970; 2: 966-8.

\section{Dr. G N Lucas}

Consultant Paediatrician LRH

\section{Dr. P M G Punchihewa replies:}

I thank Dr Lucas for his comments on our paper.

While we acknowledge the work done by Mirando et al in 1967 and 1970, the fact that there have not been further publications since then confirms our statement that "lead poisoning has not been documented much in Sri Lanka". 
